\title{
Becoming professional tech journalists - beginnings of a new social category. From Reality Hackers to a reality check: Origins of Wired (1984-2003)
}

\author{
Camille Akmut
}

February 18, 2022

\begin{abstract}
brief
Technology journalists transitioned from fairly obscure figures to in demand stars of the news and publishing world. This work retraces the origins and ascension of this now dominant social group, producers of ruling discourses; based on largely forgotten publications of the 1980s as well as better known, experimental magazine Mondo 2000. Up to St. Jude's death.
\end{abstract}




\section{I high frontiers a drug, science, art newspaper of the $1980 \mathrm{~s}$}

In the beginning there was a modest newspaper called High Frontiers that covered "Psychedelics, Science, Human Potential, Irreverence \& Modern Art". "A S.F. Bay Area Publication" of about 30 pages, sold for - then 1 dollar. ${ }^{1}$

\section{1 drugs + science : mckenna, leary and the fundamental fysiks group}

Stylistically, High Frontiers set the tone for the entire series: Presented as "the Space Age Newspaper" for the topics of drugs, science and art, it would be critical of others but only so much as critical of itself, and self-derisive.

Among later features of note of Mondo 2000 were for example the publication of, often very explicit, negative, reader feedback (along the lines of about "you complete fuckers, idiots"...), as well as various linguistic shenanigans that resembled or were derived from elite academic culture or hacker tradition : e.g. circles like the Fundamental Fysiks Group, associated with Berkeley, or early hackers as found at MIT.

To give a few examples only : the usual "table of contents" is replaced by a "table of contexts" in one of the issues, and by "offerings" in $\mathrm{R} 6$, readers writing letters to Reality Hackers were in turn called "reality hecklers", etc. The staff addressed readers with the uncertain, affectionate "Dear Mondoids" (e.g. \#4)

In High Frontiers's "premier issue", members of those societies were represented such as in particular in the person of Jack Sarfatti.

Thematically, High Frontiers set the standard for at least two corner stones of later publications (like Mondo), drugs combined with science : Contributors of that first issue included Terence McKenna and Timothy Leary, musing about space and time, and sperm, and of course their topic of predilection, drugs were never far away.

However, in the case of Leary, drugs were a means to an end, namely research on intelligence increase which he felt was a pressing matter following his release from prison (as explained at the beginning of the 1987 issue). In Leary's mind, at least, drugs were a way "[of] turning yourself on, booting up your brain, activating new circuits in your mind."

For McKenna (who wrote a column-style "psychopharmacognosticon"), drugs seemed to be a way a way to break with deeply ingrained societal normal states, and established norms, as well as a means to understand human evolution as

\footnotetext{
${ }^{1}$ High Frontiers, "premier issue" cover.
} 
part of re-written history of mankind where drugs were according to him a key factor in the evolution of humans ${ }^{2}$.

Other writers close to them would later join in : Ram Dass in the next issue, for instance, Andrew Weil in this one.

Weil, another graduate of Harvard, "a medical doctor and nationally recognized pharmacologist", explained his introduction to the subject so :

I was to start my Freshman year ... and I was in a course called "Sociology in American Society." We had to write a term paper, and I wrote on the subject of "Drugs in Society." That gave me an excuse to read everything on the subject and I came upon Aldous Huxley's book The Doors of Perception. He was uo at M.I.T. that year, this was the fall of 1960, lecturing on visionary experience. I wrote him a letter and asked him where I could get some mescaline

3

As for the second corner stone of this publication - namely, science - it would be laid with the inaugural Nick Herbert "Fringe science" column in issue 2 of High Frontiers; a tradition that would endure throughout modifications all the way to Mondo's (symbolic) end.

Together with Sarfatti, and later Saul-Paul Sirag (Mondo), they would be constitutive of High Frontier's and then Mondo's science department. Their connection? The Fundamental Fysiks Group, an association of physicists that melted science and philosophy, around Berkeley.

Perhaps the best known historical antecedent was the, so-called, "School of Vienna"4.

Characteristic of such groups were the grouping of scientists together with philosophers and historians, and other like-minded people; they did not share the aversion for the humanities that unfortunately characterizes some of their successors. $^{5}$

\section{2 art and lifestyle: wilson, burroughs, and "durk and sandy"}

Finally, the art corner stone of this older publication was represented by such writers as Robert Anton Willson (\#2), Burroughs (\#3), both of which would re-appear in issues of Mondo.

Meanhile the "Human Potential" thematic was furthered, in addition to Leary's intelligence enhancement, by the appearance of long time collaborators Durk Pearson and Sandy Shaw, who wrote -and sold- a variety of "life extensions" tips and products, as well as "designer" solutions (e.g. food, lifestyle), often referred to as simply "Durk and Sandy".

\footnotetext{
${ }^{2}$ See his incalculably numerous lectures and talks, e.g. Alien Dreamtime, and his book Food...

3 issue 1, p. 8.

${ }^{4}$ See Jean Cavailles' review, of which we have produced a translation.

5 (we leave the question of whether this trait is to the detriment of their 'hard science' aside)
} 
Artists like Bę̧tie Boys and Todd Rundgren were interviewed, featured (\#4).

\section{3 fourth issue : introduction of "reality hackers"}

Thematically, still, the first two to three issues of High Frontiers were more reminiscent of 1960's counter-culture literature, despite their 1980's publication date, than the later explicit cyberpunk affiliations and leaning of Mondo 2000.

A significant changed occurred with issue 4 of High Frontiers, whose table of contents read :

\section{STEAL THIS DECADE: THE SIXTIES! \\ ... \\ INTO THE NINETIES: THE REALITY HACKERS TAKE OVER! \\ Illustration : section titles in High Frontiers' fourth issue}

The fourth issue of High Frontiers made it clear : keep the 1960's, if you want, here come the hackers - by which motto they meant to clarify their increasing interest in, and orientation towards electronics, computers and their counter-cultural uses.

On the occasion of issue 4 , a hacker convention was visited and became the location of an interview;

A special section was dedicated to new technologies;

Leary was interviewed as part of a piece echoing the format of the film $M y$ Dinner with Andre, including thoughts on nanotechnologies.

The allusion to My Dinner with Andre merits a detour, as this reference is quite representative for the magazine's later interests : the film's arguably most memorable segment is a mind experiment along the lines of contemporary adaptations of Cartesian doubt "What if this is all fake and we live in a simulation" (culminating in the popularity of 1990's mega-success The Matrix, and found since everywhere from entrepreneur tweets to hit animation Rick and Morty), applied to the specific issue of New Yorkers' apparent inability to leave their city despite much complaints and attempts to do so.

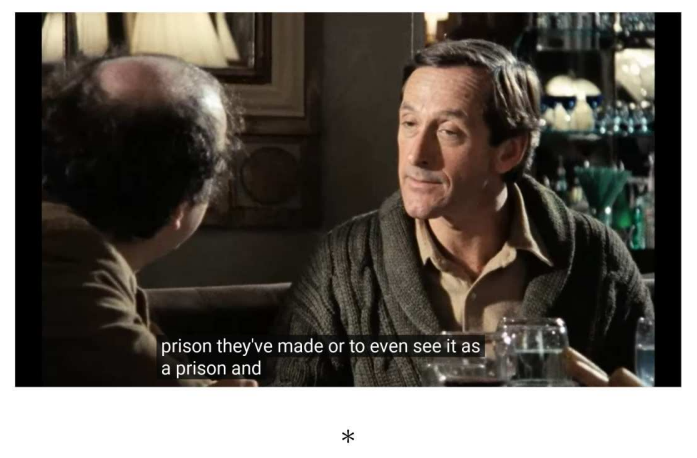

R.U. Sirius, Somerset Mau Mau and Queen Mu were publishers. 


\section{II reality hackers transition to the 1990 s}

A major contributor was still mostly missing from High Frontiers, to push its slightly outdated style towards modernity : the legendary hacker Jude Milhon, a.k.a. St. Jude, made a brief appearance in issue 4 under the "Proofreading" staff section but only became an editor in the follow-up magazine.

The 1987 High Frontiers issue announced a newsletter that would bring readers "new information from the frontiers of technology and consciousness" 6 , called Reality Hackers. Whereas the former was an annual publication, the latter would appear more frequently. It also reflected a shift in interests.

\section{1 thematic shift towards "information technologies"}

Issue 5 of Reality Hackers was a complete break with the former hippie-andspace newspaper, it now featured the following modern subtitle:

Information technologies \& Entertainment [for Those on the Brink]

It had now shed its former Beatnik culture meets space age enthusiasm for science origins, and understood its new mission to be the coverage of computer technologies.

However, Reality Hackers was not to be a mere straight-down-to-facts-andspecs publication (a la Byte),

As its revised subtitle made evident, the vision was of a cool tech magazine that should be different from what had existed. It proposed to do that by mixing new tech with sex and cultural tour de force writings, and the drug gurus' teachings (which could be kept).

\section{2 fortunate intuition : computers are sexy}

Another new orientation was the melange of suggestive imagery put in contrast with hard computer facts and heady essays.

The ever of issue 5 of Reality Hackers, in addition to a new thematic, also announced new aesthetics that would characterize Mondo's distinctive style, recognizable among thousand, namely the here born, fortunate intuition that mixing computers with sex was probably not such a bad idea.*

\footnotetext{
${ }^{6} \mathrm{H} 4$, Front page.
}

*Beyond the general idea that sex sells, the publishers of Mondo were not alone in this, but could look back on a long tradition of sexualized computer imagery (see in part. ad campaigns for systems such as Digital Equipment Corporation's PDP : miniskirts, boots, possibly inspired by Stark Trek costumes). For contemporary magazines : Amiga Magazine, Your Amiga (04/1990) .... from the same period. 


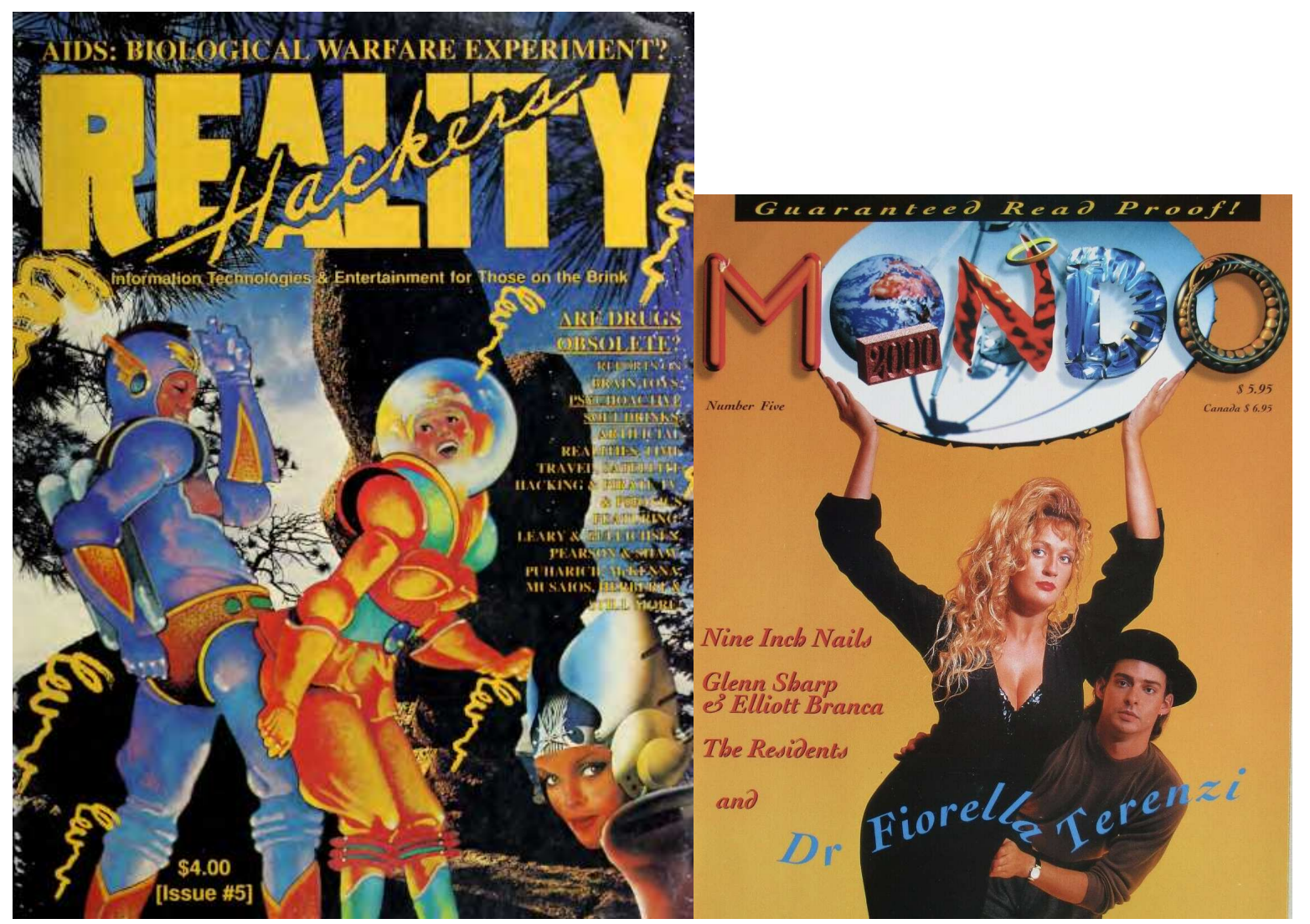

Illustration: issue 5 Reality Hackers cover (l), Mondo 5 (r) comparison

Mondo 2000's issues - systematically headed by women on their covers popped out from any kiosks and vendor racks, among otherwise mostly gray, uninspired IT tomes.

First experiments leading to this distinctive new genre of literature happened in Reality Hackers, issue 5 showed two space enthusiasts having a good time and rubbing and frotting (to unheard rhythms).

In issue 5 of Mondo, shown here for comparison purposes, the male and female cartoon characters were replaced by their human counterparts in similarenough positions (the subject of the cover being, real-life, astrophycist Fiorella Terenzi).

But, just who was Reality Hackers for? The fifth issue provided an answer, by clarifying who the so-called "reality hackers" were, in the first place.

1. USING HIGH TECHNOLOGY FOR

A LIFE BEYOND LIMITS.

2. EXPANDING THE EFFECTIVE- 
NESS \& ENJOYMENT OF THE

HUMAN BRAIN, MIND,

NERVOUS SYSTEM \& SENSES.

3. BLURRING THE DISTINCTION

BETWEEN SCIENCE FICTION

\& REALITY.

4. MAKING BIG BUREAUCRACY

IMPOSSIBLE.

5. ENTERTAINING ANY NOTION USING WHAT WORKS.

6. INFUSING NEW ENERGY INTO

POST-MODERN CULTURE.

7. USING HARDCORE ANTHRO-

POLOGY TO UNDERSTAND

HUMAN EVOLUTION.

8. USING MEDIA TO SEND OUT

MUTATIONAL MEMES

(THOUGHT VIRUSES).

9. BLURRING THE DISTINCTION

BETWEEN HIGH TECHNOLOGY

\& MAGIC.

10. REPLACING NERD MYTHOLOGY

WITH SEXY, HEALTHY, AESTHETIC \& ARTFUL TECHNO-

MAGICIANS OF BOTH GENDERS.

We reproduce this document in full due to, our perception of its importance : another such explicit exposition of objectives is not known to us. ${ }^{7}$

The answer they provided made once again clear that the publishers' and editors' interest lied not only with computers but their intelligent, useful, or weird or sensual applications (anything beyond dominant, commercial uses, essentially) : they wrote about "reality hackers" seeking joy, for themselves and others, aliewating pain, nuisances, threats (e.g. bureaucracy), knowledge (through their proposed revisions of anthropology and new interpretations of contemporary culture), against dogma ("using what works), etc..

\footnotetext{
${ }^{7} \mathrm{R} 5$, Front page.
} 
The reference to, specifically, "hardcore anthropology" to serve a new vision of human development seems to be a reference to fellow collaborator McKenna.

The next nearest document is a description of contents to expect, as it appeared at the end of issue 6 :

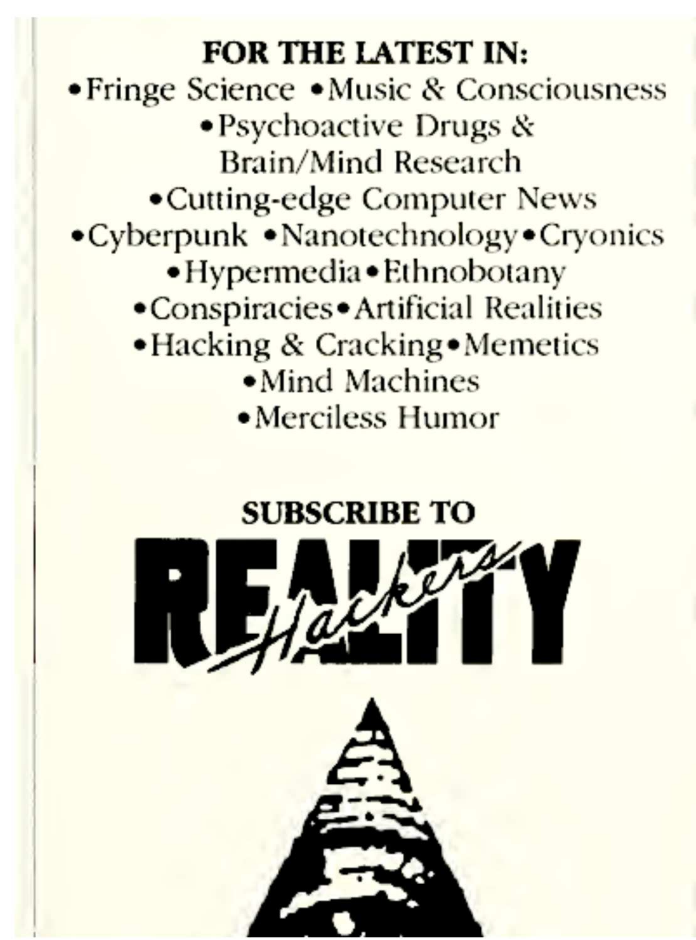

Illustration: issue 6 Reality Hackers end

\section{3 wider changes in society}

High Frontiers' succession by Reality Hackers, and ultimately Mondo 2000 can also be related to wider societal changes. The transition lied somewhere between :

i. computers, previously machines associated with academic labs and military installations as well as their belonging and property, had become within reach of the middle classes at the end of the previous decade (the close releases of popular Apple, Commodore, Tandy/Radio Shack offerings), both due to households friendly cheapening and living-room or even bedroom compatible miniaturization.*

ii. initiatives like the GNU operating systems, the liberation of the BSD code from AT\&T legacy parts, restrictive licensing and fees (the "Net" releases, in part.) in the 1980's.

iii. democratization of the internet outside university elites and expert, hacker circles - by roughly the mid-1990's, $5 \%$ of the World had now access to it - and the co-introduction of the web 
To sum up : the 'personal' computer extracted this new object from previous strongholds and put it in everyone's homes; free software was the translation of hacker culture ideals, and made it possible in the domain of computers; the internet and web created a massively-connected world;

The mythical T1-3 lines (e.g., mentioned in the more cyberpunk leaning episodes of X-Files) were replaced by relatively cheap, unspectacular $28 \mathrm{k} / 56 \mathrm{k} / \mathrm{ISDN}$ modems that made browsing and playing online games bearable, popular (before current high-speed). And while not everyone could transform their operating system, soon everyone could install a "Linux distribution" as found on the CDRoms of thick IT magazines;

issues previously only explored theoretically in science fiction had now crossed over to reality. Mondo was one of the publications that took them seriously, when few others would - then.

\section{4 increase in polish and professionalization}

In Reality Hackers issue 6 - almost twice as thick as the previous one - the table of contents sees the introduction of sub-topics (letters, columns, features) that would be kept in Mondo's organization, and can be regarded as a movement towards ever more professionalization.

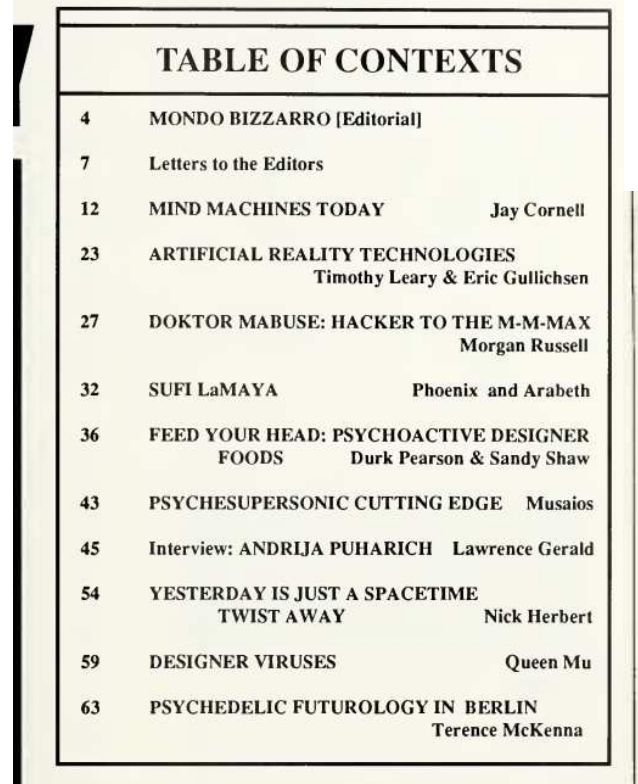

\section{editorial}

4 SOAPBOX

by Jas. Morgan and accomplices

\section{HACKER BIOS}

\section{REALITY HECKLERS}

Letters to the Editor

\section{columns}

\section{FRINGE SCIENCE}

by Nick Herhert

Illustration: issue 5 Reality Hackers, table of content / 6, the same

In terms of design, Reality Hackers had improved when compared to previous offering High Frontiers, and was more polished, and cool, while never reaching the heights of Mondo 2000 under Bart Nagel (although charming, on its own). 


\section{III mondo 2000}

"Mondo 2000 is published quarterly" its inside pages said ${ }^{8}$

During its existence, it managed to create a unique publication based on a formula steadily improved from iteration to iteration $-\mathrm{H}$, $\mathrm{R}$, now $\mathrm{M}-$ melding computers and elements of modern counter-cultures (drugs, sex, hip-hop)...

"More polish, less (of the) explosive" could be the formula behind Mondo 2000, when compared with its direct predecessor Reality Hackers.

\section{1 content focusing : more computer-centric material}

In one of the issues ${ }^{9}$ Mondo claimed to be 'the most subversive/dangerous new magazine'.

But, if this was true, the more risky articles were now to be a thing of the past. Instead more and more articles were computer-centric :

In fact, what turned out to be the first issue of Mondo 2000 was originally conceived as, supposed to be a cyberpunk special issue of Reality Hackers, and was announced so in its pages.

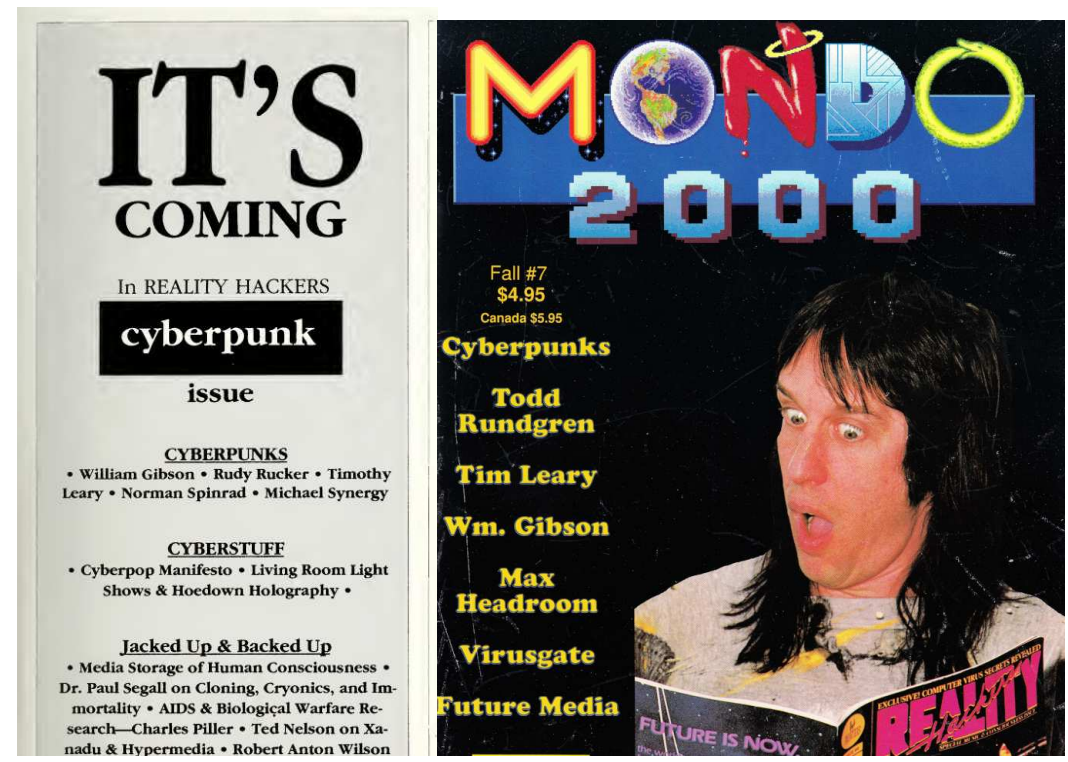

Illustration: issue 6 Reality Hackers end / issue 7,., - 1 of Mondo 2000

The cover even bears the mention of "issue \#7" and makes this lineage clear though the imagery of a reader holding a Reality Hackers issue (the previous issue, 6, with Sun Ra) despite the, new, "Mondo 2000" title.

\footnotetext{
${ }^{8} \mathrm{M} 4$ staff.

$9(5,9 ?)$
} 
Gone the articles on AIDS as a "designer virus" or "biological warfare experiment", relegated to yesteryear. ${ }^{10}$.

In later issues, when it came to technically sound articles, Norman French regularly provided some of the best coverage of this magazine : the most memorable of which probably the series of PGP articles ${ }^{11}$.

Mondo's claim to subversiveness was nonetheless serious

While we won't re-print the pictures of e.g. peeing babies, nude photos of Michael Jackson were shown (in a photo collage/montage?) with what appears to be female genitalia ${ }^{12}$. Meanwhile Oridge's icogonography blending gory, sexy, and the bizarre and obscure still provided plenty of material to be shocked or angry about, and would unlikely be published today (in Wired, or most other places elsewhere). Androgyny, gender-bending was also regularly included.

As for the sex appeal dimension of this publication, no changes were further made to this winning formula.
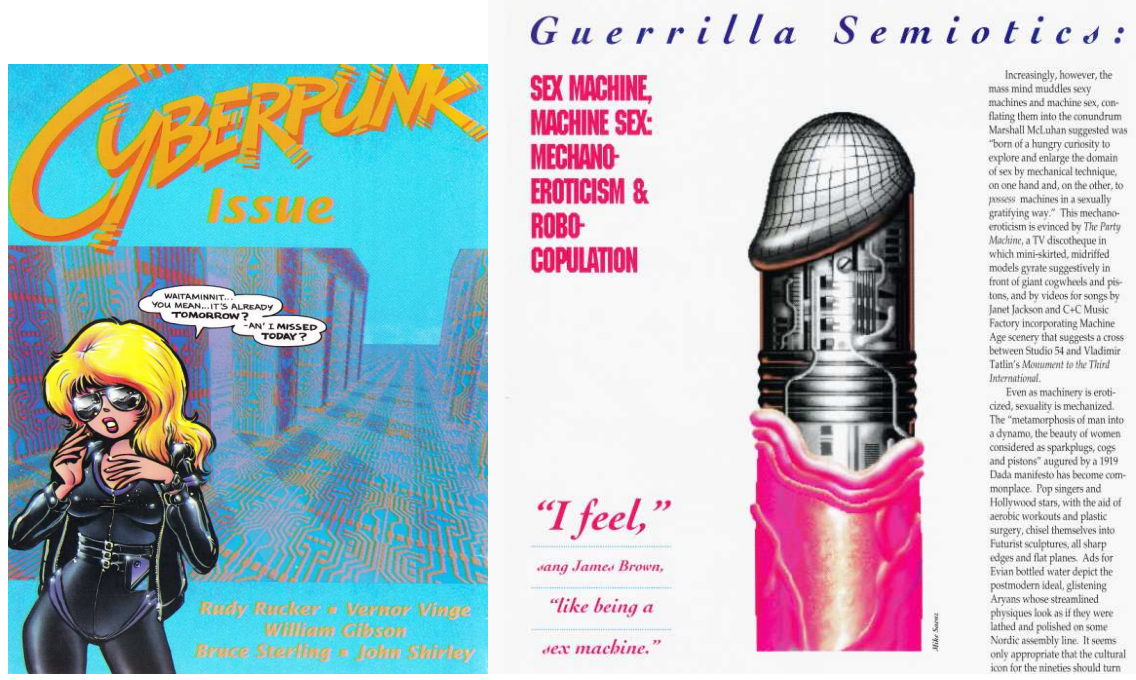

Illustration: issue 1 and 5 Mondo 2000

Cyber-Babe: "YOU MEAN... IT's ALREADY TOMORROW?"

\section{2 experienced staff and long-time collaborators}

Contrary to previous iterations, which sometimes could be very rough (HF's "premier issue") or relied on fairly new personnel, Mondo 2000 enjoyed now a mostly experienced staff assembled over half-a-decade of prior errors and trials.

\footnotetext{
${ }^{10}$ For example, R 5. The reader would search in vain trying to find anything even remotely close or comparable in their latest issue of, supposedly subversive, Wired magazine...

${ }^{11} \mathrm{M} 5,9$.

122102
} 
The core members of staff of Mondo emerged as :

- R. U. Siruius (editor-in-chief),

- Queen $\mathrm{Mu}$ (in a neology rank above everyone else's),

- St. Jude (senior editor),

- Bart Nagel (art director),

- Jas. Morgan (as music/arts editor),

Many others contributed over the years, some disappearing along the way, others rising in rank, e.g. publishers and editors Morgan Russell, Michael Synergy, Hultkrans, art director Foley...

They received continued support and cooperation from long term collaborators McKenna, Herbert, Leary, Durk and Sandy, Robert Anton Wilson... - to which was now added heavyweight John Barlow (a contributing editor from issue 4 on).

Joi Ito was listed as a Tokyo correspondent (due to Leary?). The latest trends from Japan regularly appeared in the magazine (by other people).

\section{3 golden age}

During its existence, Mondo managed to create a unique publication based on a formula steadily improved from iteration to iteration $-\mathrm{H}, \mathrm{R}$, now $\mathrm{M}-$ where cyber age pin-ups (covers), avant garde cultural criticism (e.g. Dery ), the best of current science fiction (Gibson, Vinge, Stephenson...) encountered solid technical exposes (on e.g. then-just-released encryption solutions), always elevated by philosophical texts provided by members of the Fundamental Fysiks Group and political discussions of latest legal threats and soon to be passed laws (prison, patents, etc, ${ }^{13}$ ).

Issue 1 brought together the original hackers Lee Felsenstein and Richard Stallman : respectively a second generation (hardware) hacker from California, and the 'last true hacker' whose profile concludes the reference book Hackers.

Felsenstein had been involved in the Homebrew Computer Club (where Apple's founders found much inspiration, before hastely closing their systems despite having greatly benefited previously from the exchange of knowledge that characterized this group of tinkerers), and the Community Memory Project, a democratic initiative aiming to give everyone access to a -digital-forum.*

\footnotetext{
${ }^{13}$ e.g. HR4079 in \#3, Stallman's "UN Treaty" in $4 \ldots$
}

*Computers were put in everyday places and people could add items and find items written by others based on keywords. Cf. Colstad/Lipkin 1975, ACM Computer and Society 6(4) 


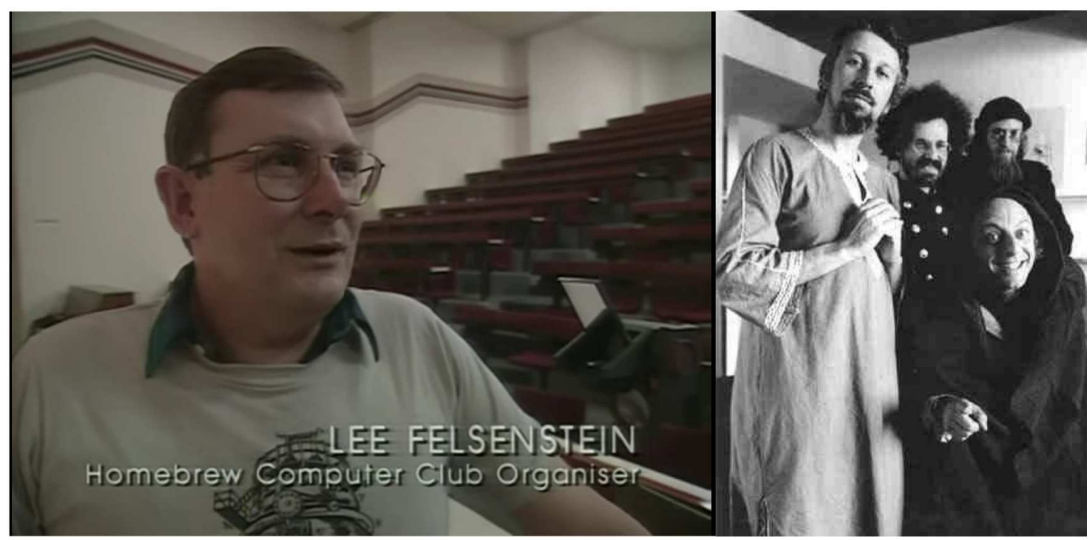

Il. : Felsenstein in Triumph of the Nerds (1996); Fundamental Fysiks Group

Stallman, then unburdened by the pro-corporate think tank Open Source Initiative, was able to express his full views on software and property, which he has since then never done with such ardor, partly due to the influence of the OSI as a "more flexible" representation of free software... :

Interviewed by R.U. Sirius, he concluded in quasi-Marxist terms :

\section{"PEOPLE WHO SELL SOFTWARE ARE CRIMINALS"}

M2: Your value system would not necessarily prevent you from taking from people who are trying to be proprietary, from grabbing it, using it, and making your own changes.

RS: Right. Software hoarding is a crime. If I can thwart that crime successfully, protect its victims, then I will do it.

All the people who sell software are guilty of this crime.

M2: This idea that information should be free, is this something that is specific to computers? What about works of art or bootlegging records...

RS : I would say that whenever something can be copied by the general public, the general public has a right to do so. The more society becomes information instead of material objects, this question of whether a person can copy things will make the difference between a world of universal prosperity or a world of constant rat race. You can create so much artificial scarcity by owning information. Once the great bulk of the things we value is information, the only thing to do is eliminating ownership.

14

\footnotetext{
${ }^{14}$ Compare with current day Richard Stallman's defense of some aspects of capitalism, such as having nice specialty food products, etc. He opposes what he calls "out-and-out socialism" Old age does not bring wisdom, always, and perhaps young Richard can teach old RMS something. [news item 14 feb. 22]
} 
Issue 3 covered the, nascent, EFF (interview with Barlow, among others).

Nick Herbert regularly contributed thought-provoking, interesting essays (e.g. "when metaphysics will be outlawed, only outlaws will do metaphysics"). In that same issue he wrote, for instance:

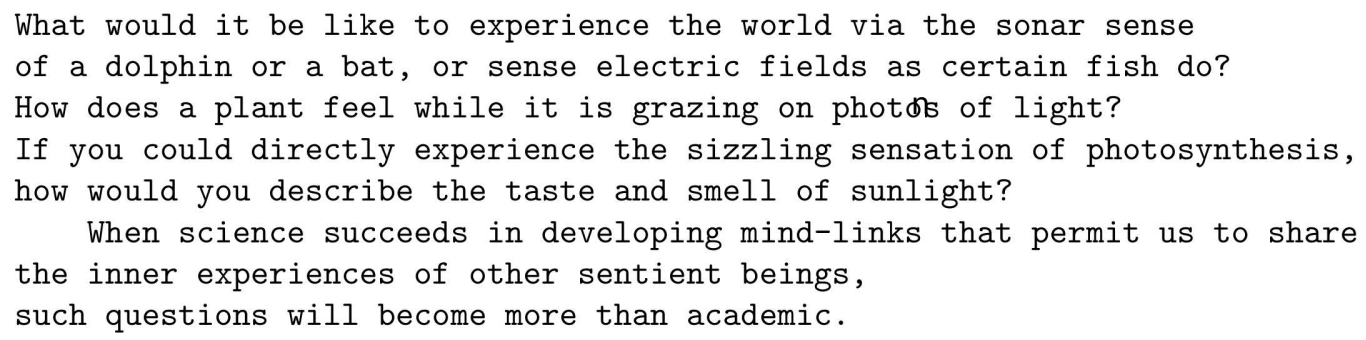

Issue 3 was also the occasion of an ethnographic-style excursion to SIGGRAPH (one of the ACM special interest groups); where cool computer animations can, sometimes, be seen.

Issue 4 featured a conversation with Hip-hop group Digital Underground, including critics of the label system (which Cornel West would no doubt call "back on the plantation").

Issue 5 had the excellent articles on Phil Zimmerman's fight against upcoming legislation as context for the creation of PGP (followed up in issue 9).

6 contains an article on Peter Chung. Aeon Flux has philosophical themes in common with Ghost in the Shell, e.g. the issue of memory and personality persistence across multiple/artificial bodies. Hence also its succession by an article on cyborg (bodies) makes sense, in this context.

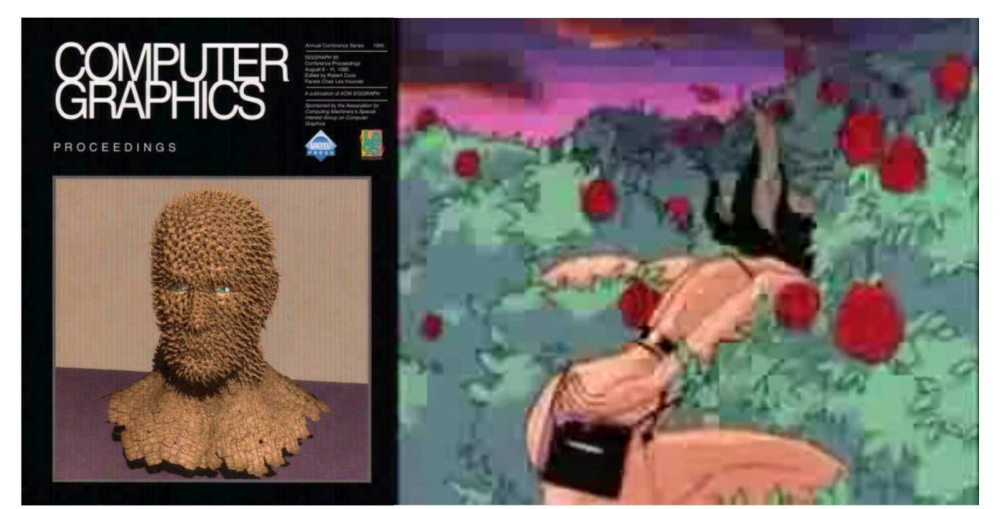

Illustration : SIGGRAPH Proceedings 1995; Aeon Flux (1991-1995)

One part of their publishing activity consisted in re-publishing and bringing to a new audience and generation classic pieces of hacker literature (such as in part. "Hacker Conscience" by The Mentor, from magazine Phrack); 
At other times it published excerpts from works it thought interesting (such as Cronenberg on Cronenberg in 8)

Issue 7 was short (110 pages, compared with over 130 for both preceding issues) and belongs to the weakest. It marked a first sign of decline.

Issue 8 was better : Sarfatti and Herbert were in conversation, exerts of a book on Cronenberg...

Issue 9 was arguably the last bang before the end : it included the second article on PGP, Linklater...

Issue 10 had old guests among whom Terence Mckenna (as if to say goodbye).

\section{4 symbolic end}

In issue 11, R. U. Sirius became an "Icon-at-Large", Jude Milhon was downgraded to "Cyberpranx" editor. ${ }^{15}$

Issue 12 was the infamous Paul McEnery issue : Paul McEnery speaks. Paul McEnery on Paul McEnery. Paul McEnery on the importance of Paul McEnery... ${ }^{16}$

Meanwhile, remaining long-time staff Wes Thomas and Jas. Morgan attempted to maintain the old editorial line. But, no St. Jude, no R.U. Sirius, the magazine is dead. is mentioned

In issue 11, already, Wired $I$ and the new Mondo seems to associate themselves with them, as if equals. ${ }^{17}$

In 1992, the magazine published its first book ( $A$ User's Guide to the New Edge.

The same year Boing Boing published a parody of the magazine's -now recognizable- format and style.

In 1993, a weak Mondo issue appeared with mostly forgettable pieces (10).

Mondo had done so well (in the genre it had created for itself) that it outdid itself and made itself useless. Now every magazine was a "mondozine". The most baffling example being Time Magazin'es february 1993 issue on... "Cyberpunk" (realized by some of Mondo's staff).

In 1995, the Cyberpunk Handbook: The Real Cyberpunk Fakebook was published at Random House (ed. R.U. Sirius).

A few years later Mondo stopped publication altogether.

\section{5 final stages of professionalization}

The design of Mondo reached new heights with art director Bart Nagel.

The table of contents of issue 2 - in which he appears credited - becomes notably more stylized (compare with the first issue).

\footnotetext{
${ }^{15}$ By 1995, R. U. Sirius had still the emeritus status of "icon at large" while Jude Milhon leaned way as "contributor editor" (14?).

${ }^{16}$ In case some readers wondered also "whoever that is, and whatever hole he crawled out of" : he was in 10-11.

17 p. 35
} 
When Milhon is promoted to Senior Editor in issue 5 she uses "Jude Milhon" for credits, rather than St. Jude.

Issue 9's most profound change is the introduction of the category of 'tech editor' (given to early collaborator Wes Thomas (writer and publicity for the first two issues). Another sign of many, of professionalism displayed outwardly.

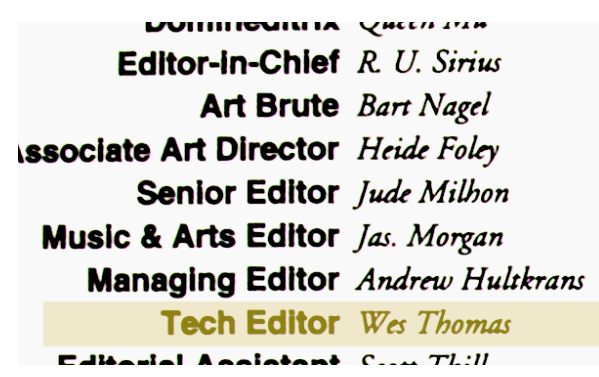

Illustration : issue 9 Mondo 2000 (staff section) 


\title{
4 wired : into the 2000s
}

Early articles were written by former Mondo 2000 staff or contributors.

Its style was clearly inspired by Mondo's (formatting table of contents, reader feedback, sections and columns e.g. "Electrosphere"...).

WIred marked yet another step towards professionalization : it emerged as a publication where cool ads - as seen prev. in Mondo ${ }^{18}$ - were becoming aggressively omnipresent almost indistinguishable from the edgy articles that appeared in-between them. Ads such as by Intel, Digital DEC (comparing themselves to a high-speed train...), HP, luxury cars, CK, Guess jeans, drinks etc. could be found ad nauseam on the inside.

\section{1 the first five years}

While already much more mainstream than Mondo 2000, Wired continued at least in the first 5 to 7 years to publish uneasy pieces : Among them were now classics, many due to Mondo's collaborators :

In 1993, Gibson's "Disneyland with the death penality" appeared, describing his impressions of Singapore as a mix of super sophisticated tech and very strict laws, customs.

In 1994, R. U. Sirius and St. Jude could be found among few writers.

\section{The Medium is the Message and the Message is Voyeurism}

\author{
By R.U. Sirius with St. Jude \\ he's permed, chubby, hose 'n' heels... Mom. She stands and girls - criminals, perverts, or cultural dissidents - \\ Illustration : Wired 19942
}

In that same year, John Barlow was also represented ("Jackboots on the Infobahn", 4), who described Clipper as "last ditch attempt by the United States, the last great power from the old Industrial Era, to establish imperial control over cyberspace."

R. U. Sirius published a stand alone article ("Pomo To Go"), in 6.

In 1995, St. Jude gave a noted interview, containing the famous quote, "Girls need modems." 19

\footnotetext{
${ }^{18}$ See the ads of companies like Sense- 8 or Lapis...
${ }^{19} 2$.
} 


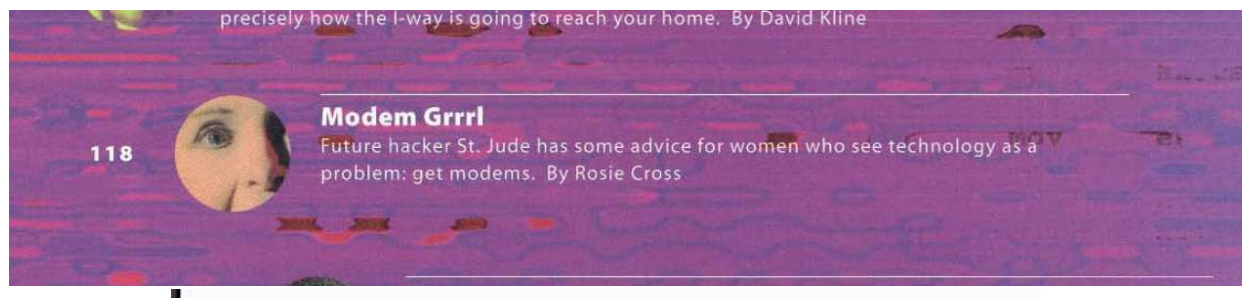

Wired: What do you think about feminism and technology?

St. Jude: I think tech will solve all our problems, personal

and scientific. Girls need modems.

Illustration : Wired 1995 2, contents and interior

Eno became one of the covers of 1995 (\#5).

In 1996 Wired called the "Fall of the EFF" on its cover.

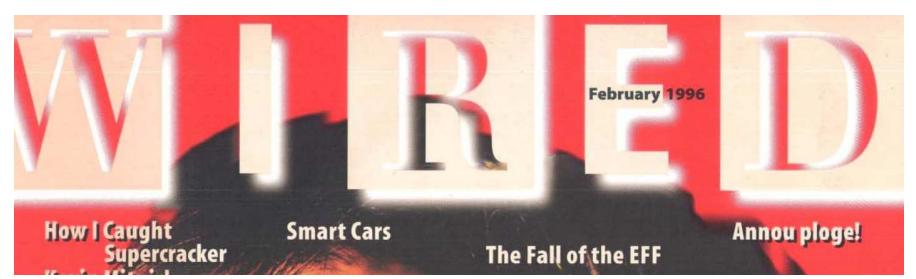

Illustration : Wired 1996 2, cover and contents

The Electronic Frontier Foundation went to Washington to "hack politics

down to its constituent parts." Then it helped pass the FBI's loathsome

Digital Telephony Bill. And discovered it was Washington that had reverse engineered the EFF, driving it into dissension, debt, disgrace - and right out of town.

Mondo's love affair with Barlow and the EFF came here to a stop if not an end.

Their critique targeted the (admitedly risible) liberal's never dying dream of "changing things from the inside", as they say, until the inside changes them invariably. Aaron Swartz belonged for much of his life - except arguably the end - to this unfortunate category. Cory Doctorow is another such figure, whose pathological interest in reformist politics would be deserving of a new inferno circle.

In 1996, still, Levy's hard hitting "Clipper chick" appeared - a play on words about a certain female cryptographer (due to cozy relationships with NSA).

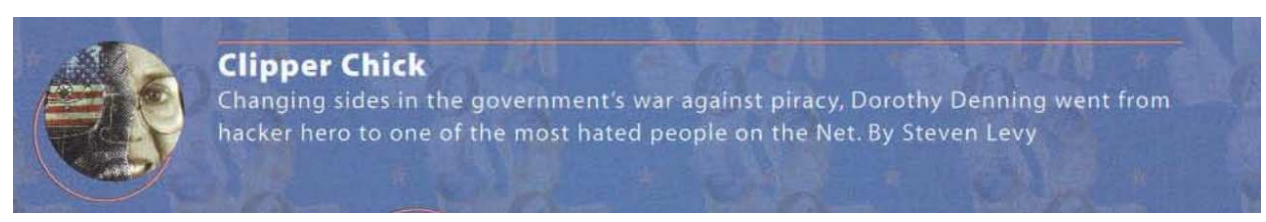

Illustration : Wired 19969 
Although "soft" by Reality Hackers standards, multiple of these articles would be probably difficult to publish today (except R.U. Sirius' forray into anti-communist cultural essays, that one not).

\section{2 the professional journalists}
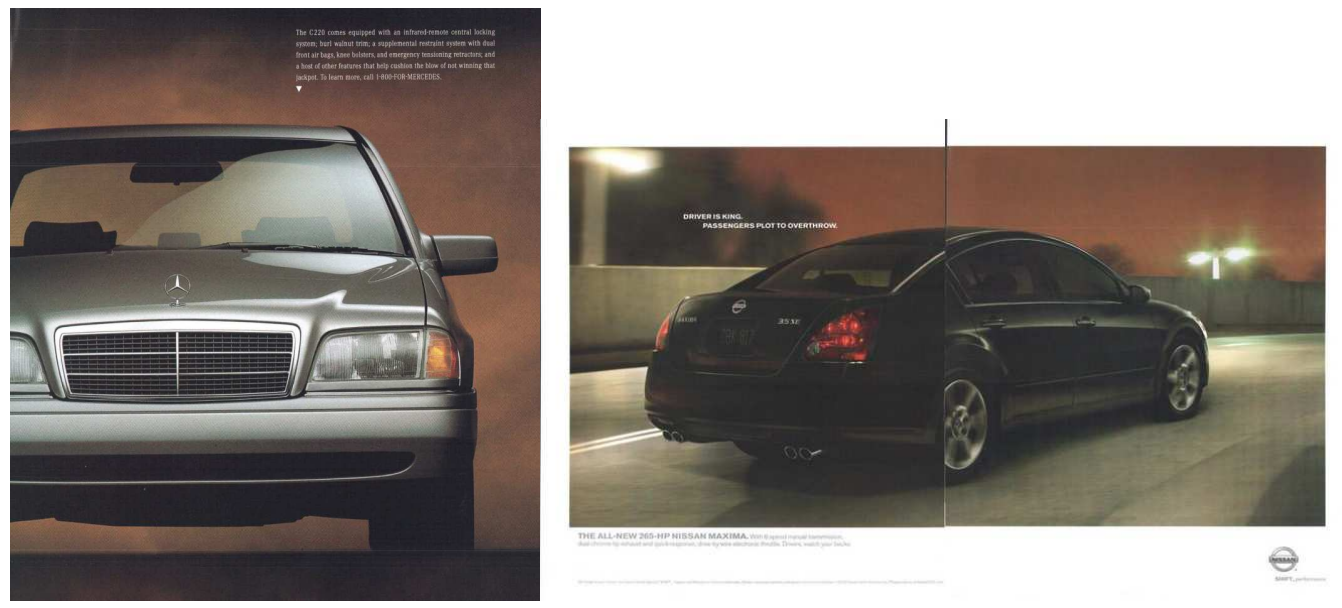

Illustration : ad examples $(1996,2003)$ Wired

The last phase past the few first years of existence of the magazine is one of rapid corporatization and turn towards the mainstream - coinciding with its sale and massive editorial change.

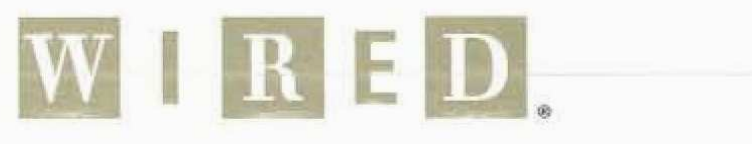

Editor in Chief: Chris Anderson

Illustration : staff (2002) Wired

Cool ads meet - sometimes indistinguishable - edgy articles, was the new formula of this magazine, culminating in the sale to Conde Nast in 1998 and the new millenium, Chris Anderson (Mr. equations) line and era.

"We decided to put the Internet-founding subculture behind us, and be more mainstream with technology. We banned Burning Man and drug culture and the letters TCP/IP,"

Anderson said. ${ }^{20}$

20"For Wired, a Revival Lacks Ads", New York Times 17/05/09. 
The mummification, the museufication of the original hackers behind Wired's formula hence could begin :

In 2003, St. Jude's death notice was published..$^{21}$

First signs of this shift were already visible in previous years (historical classifications, however useful, should not be too rigid, or be blinding) ;

this was in part. true in instances such as the interview of Steve Jobs ("the next insanely great thing" ${ }^{22}$ ) or when Wired's, now professional journalists called Ray Smith of Bell "the smartest telco CEO" 23 .

Journalists' role was not anymore to highlight the fringes of technology, it was not to shed light on what happened in the shadows of mega-corporations, it was not publishing seldom heard voices in the service of, ex gratia, democracy.

No, it would be to amplify already deafening tones, and for journalists to become the faithful stenographers of new-lords, from now on.

\section{conclusion}

During glorious live-fast-or-die existences , the publications High Frontiers, Reality Hackers and Mondo 2000 managed to do many things :

One of Mondo's achievements - in an era before diversity and inclusion politics and rhetoric - was to create an intellectual space where pioneering hackers and crackers met hip hop groups, trans. artists, outsider scientists...; thus creating a truly diverse and unique location in space and time - accessible infinitely through archives - that stands in bitter, bitter, oh so stark contrast with most journals and magazines published today.

Those courageous few who want the more sweat-inducing content of earlier years will find a way to back issues of " $H$ " and "R".

As the magazine evolved to become Mondo, its interest in and liberal attitude towards conspiracy, alternative and uncertain theories would play a bigger and bigger role (except My Dinner... would be replaced by more timely Slacker).

In its golden age (issues 1 to 11 - as now everyone knows), Mondo maintained a complicated balance between fringe roots and increased interest, content that remained truly shocking at times while not risking liberal consensus rejection (maybe it was just fun, or a joke!). ${ }^{24}$

This publication will no doubt come as a shock to all-thebest-opinions blessed liberals, found in such great masses in dominant places.

It treats alternative beliefs and theories cautiously, perhaps based on the intuition if not knowledge that some of yesterday's egregious madmen are tomor- 
row geniuses, and that today's truth is still not safe from the long, fermenting work of history. 